\title{
Inhibitory Effect of Metformin on Oxidation of NADH-Dependent Substrates in Rat Liver Homogenate
}

\author{
E. PÁLENÍČKOVÁ ${ }^{1}$, M. CAHOVÁ ${ }^{1}$, Z. DRAHOTA ${ }^{2}$, L. KAZDOVÁ ${ }^{1}$, M. KALOUS ${ }^{3}$ \\ ${ }^{1}$ Department of Metabolism and Diabetes, Centre of Experimental Medicine, Institute for Clinical \\ and Experimental Medicine, Prague, Czech Republic, ${ }^{2}$ Institute of Physiology, Czech Academy \\ of Sciences, Center for Applied Genomics, Prague, Czech Republic, ${ }^{3}$ Department of Cell Biology, \\ Faculty of Science, Charles University, Prague, Czech Republic
}

Received March 15, 2011

Accepted June 10, 2011

On-line August 1, 2011

\begin{abstract}
Summary
Metformin is widely used in the treatment of Type 2 diabetes, however, mechanisms of its antihyperglycemic effect were not yet fully elucidated. Complex I of mitochondrial respiration chain is considered as one of the possible targets of metformin action. In this paper, we present data indicating that the inhibitory effect of metformin can be tested also in liver homogenate. Contrary to previous findings on hepatocytes or mitochondria under our experimental conditions, lower metformin concentrations and shorter time of preincubation give significant inhibitory effects. These conditions enable to study the mechanism of the inhibitory effect of metformin in small samples of biological material (50-100 mg wet weight) and compare more experimental groups of animals because isolation of mitochonria is unnecessary.
\end{abstract}

\section{Key words}

Liver homogenate • Glutamate and Palmityl carnitine oxidation • Metformin

\section{Corresponding author}

E. Páleníčková, Department of Metabolism and Diabetes, Centre of Experimental Medicine, Institute for Clinical and Experimental Medicine, Prague, Vídeňská 1958/9, 14021 Praha 4, Czech Republic. E-mail: Eliska.Palenickova@ikem.cz

Type 2 diabetes is a progressive metabolic disorder associated with abnormal glucose and lipid metabolism. Metformin (N,N-dimethylimidodicarbonimidic diamide) has been used for the treatment of diabetes since the late 1950's (Bailey and Turner 1996) and until now is the drug of the first choice. Metformin decreases the hepatic glucose production mainly by inhibiting gluconeogenesis (Hundal et al. 2000). We have previously also shown that metformin decreases fatty acids oxidation in liver (Cahova et al. 2010).

Recently it was reported that metformin inhibits gluconeogenesis through mechanisms linked to perturbation of mitochondrial function (Foretz et al. 2010). Its effect was explained as an inhibition of mitochondrial complex I activity. The inhibitory effect of metformin was demonstrated in hepatocytes incubated with $10 \mathrm{mM}$ metformin for $180 \mathrm{~min}$ (El-Mir et al. 2000). In isolated mitochondria incubated for $255 \mathrm{~min}$ in the presence of $10 \mathrm{mM}$ metformin the oxidation of glutamate+malate+ADP was decreased by $40 \%$ but in disrupted mitochondria the inhibitory effect of metformin was only $10 \%$ (Owen et al. 2000). El-Mir et al. (2000) could find inhibition by metformin only in intact cells but not in isolated mitochondria. Recently it was demonstrated that metformin attenuates the generation of oxygen reactive species (Ouslimani et al. 2005) and inhibits the opening of the mitochondrial membrane permeability transition pore activated by cytosolic $\mathrm{Ca}^{2+}$ and ROS, which was associated with prevention of necrotic processes (Carvalho et al. 2008, Guigras et al. 2004). Despite of these findings, the detailed mechanism of metformin action on mitochondrial respiration and on complex I in particular has not been well defined yet. 
A

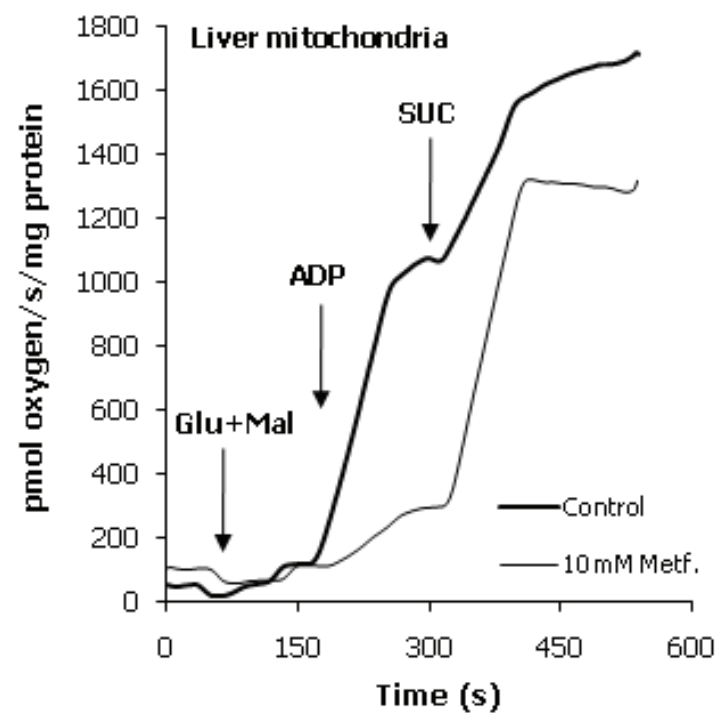

B

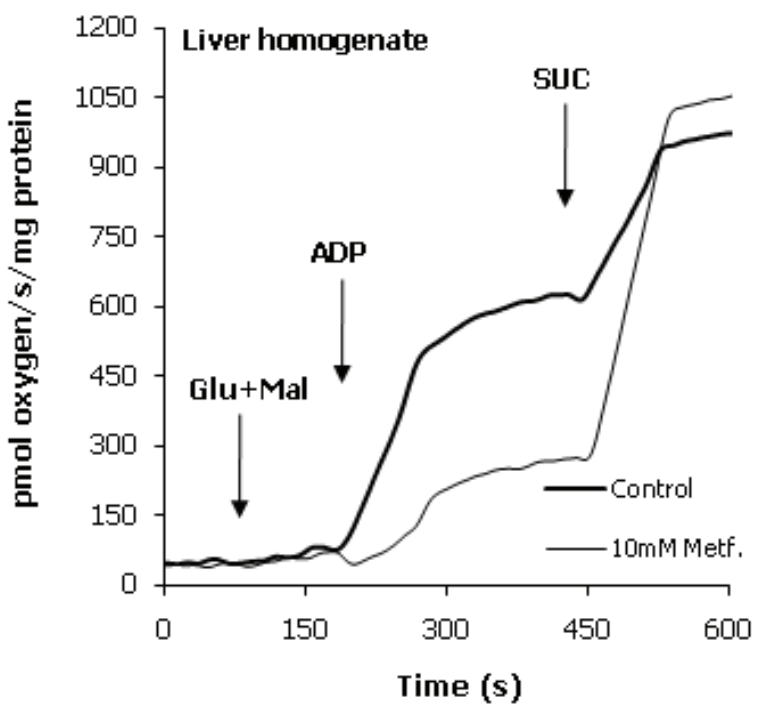

Fig. 1. The effect of $10 \mathrm{mM}$ metformin on the oxidation of glutamate and malate by isolated liver mitochondria (A) and liver homogenate (B). Respiration of liver mitochondria $(0.2 \mathrm{mg}$ protein $/ \mathrm{ml})$ or liver homogenate $(0.6 \mathrm{mg}$ protein/ml) was measured with or without $10 \mathrm{mM}$ metformin ( 5 min preincubation) in potassium medium supplemented with 0.5 mg fatty acid free bovine serum albumin per $\mathrm{ml}$ and $20 \mu \mathrm{M}$ cytochrome c. $10 \mathrm{mM}$ glutamate, $2.5 \mathrm{mM}$ malate, $1.5 \mathrm{mM}$ ADP and $10 \mathrm{M}$ succinate were added as indicated.

More data are thus required to understand the mechanisms through which metformin can inhibit mitochondrial respiratory chain activity.

We tried therefore to compare the effect of metformin on substrate oxidation of mitochondria and liver homogenate and to define conditions for such in vitro studies and we found that the metformin inhibitory effect can be well evaluated also in tissue homogenate which has not been used up to now. In our experimental design we were able to detect significant metformin inhibitory effect after short (3-5 $\mathrm{min}$ ) preincubation at a lower concentration range $(2.5-5 \mathrm{mM})$ compared with previously published data (Owen et al. 2000).

For the oxygen consumption measurements we used High Resolution Oxygraph K2- OROBOROS (Austria). Wistar male rats 200-250 g fed standard laboratory diet were used. Liver homogenate was $10 \%$ $(\mathrm{w} / \mathrm{v})$ prepared in $0.25 \mathrm{mM}$ sucrose, $10 \mathrm{mM}$ Tris- $\mathrm{HCl}$, $1 \mathrm{mM}$ EDTA, pH 7.4 medium and liver mitochondria were isolated by differential centrifugation according to Schneider and Hogeboom (1950). Oxygen consumption was registered in a medium (potassium medium) containing $100 \mathrm{mM} \mathrm{KCl}, 10 \mathrm{mM}$ Tris- $\mathrm{HCl}, 4 \mathrm{mM}$ $\mathrm{KH}_{2} \mathrm{PO}_{4}, 3 \mathrm{mM} \mathrm{MgCl}, 1 \mathrm{mM}$ EDTA, $\mathrm{pH} 7.3$ at $30{ }^{\circ} \mathrm{C}$, which was prepared with modification according to Gnaiger et al. (1995). Palmityl carnitine ((3R)-3-hexadecanoyloxy-4-trimethylazaniumylbutanoate) oxidation was determined as described in our previous papers
(Křiváková et al. 2008, Červinková et al. 2008, Endlicher et al. 2009). The protein concentration was determined according to Bradford (1976).

The data presented in Fig. 1 confirmed that metformin inhibitory effect does not require measurement in intact cell. The inhibitory effect of $10 \mathrm{mM}$ metformin could be demonstrated both in mitochondria and in homogenate after a short 3-5 min preincubation. The sensitivity of both homogenate and mitochondria to metformin was higher compared with previously published data (Owen et al. 2000).

In further experiments, we tested the concentration dependence of the inhibitory effect of metformin using glutamate+malate+ADP and palmitylcarnitine + malate + ADP as substrates. We found a significant inhibitory effect of metformin for glutamate+malate+ADP respiration and for respiratory control index already at $5 \mathrm{mM}$ concentration both for homogenate and mitochondria. Maximum inhibitory effect of metformin (about $80 \%$ ) was found in a range between 10-20 mM concentration (Fig. 2). Inhibition of "state 3" respiration was parallel with the inhibition of the respiratory control index (Fig. 2B). Decrease of respiratory control may represent another indicator of metformin action on mitochondria connected with decreased ATP production, however, further studies are necessary to elucidate this issue. 
A

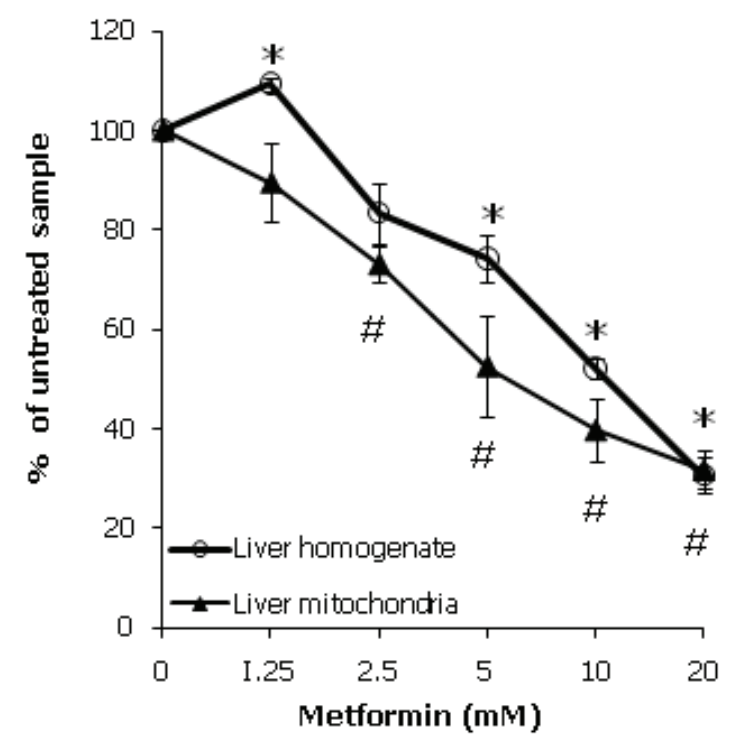

B

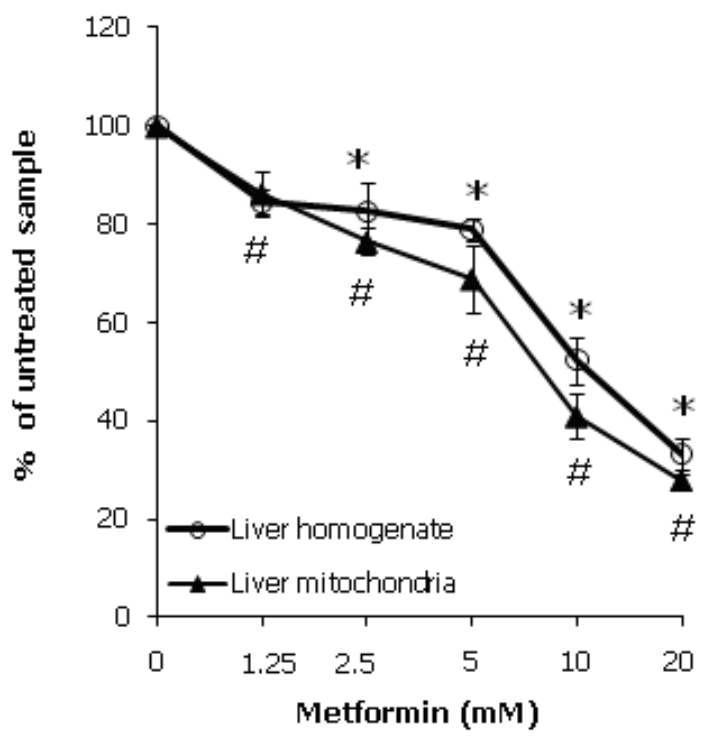

Fig. 2. The effect of metformin concentration on glutamat+malate oxidation (A) and respiratory control index (B) in the rat liver homogenate and mitochondria. Glutamate and malate-dependent respiration of rat liver homogenate and mitochondria was measured as described in Fig. 1 after 5 min preincubation with 0, 1.25, 2.5, 5, 10, $20 \mathrm{mM}$ metformin. Respiratory control index was calculated from values obtained in Fig. $2 \mathrm{~A}$ as the ratio of respiration rate in the presence and absence of ADP. $* \mathrm{P}<0.05$ vs. untreated sample (homogenate). ${ }^{\#} \mathrm{P}<0.05$ vs. untreated sample (mitochondria). The presented data represent average from 4 independent experiments \pm S.E.M. and they are expressed as percent of untreated sample values. The oxygen consumption of liver homogenate and mitochondria were $609 \mathrm{pmol} / \mathrm{s} / \mathrm{mg}$ protein and $1100 \mathrm{pmol} / \mathrm{s} / \mathrm{mg}$ protein, resp. Control values of the respiratory control index of liver homogenate and mitochondria were 7.7 and 7.6, resp.

A

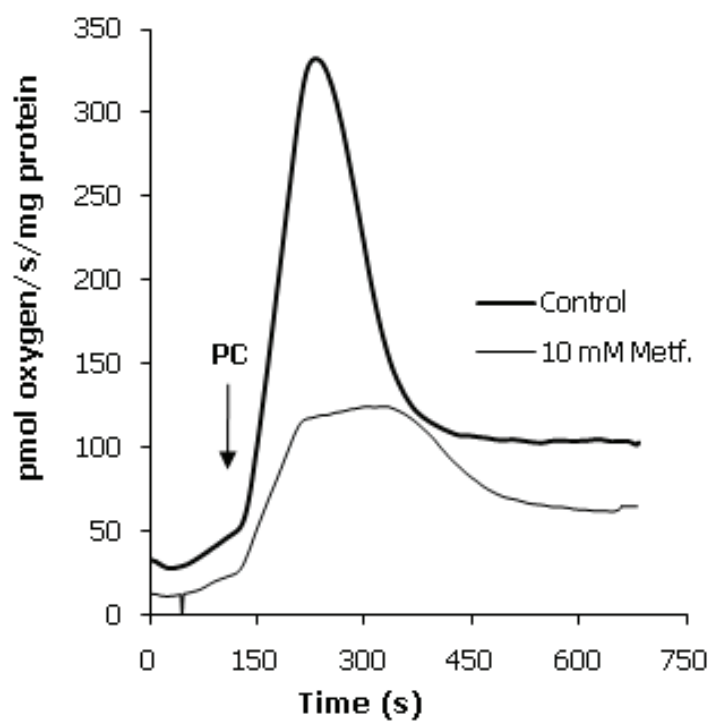

B

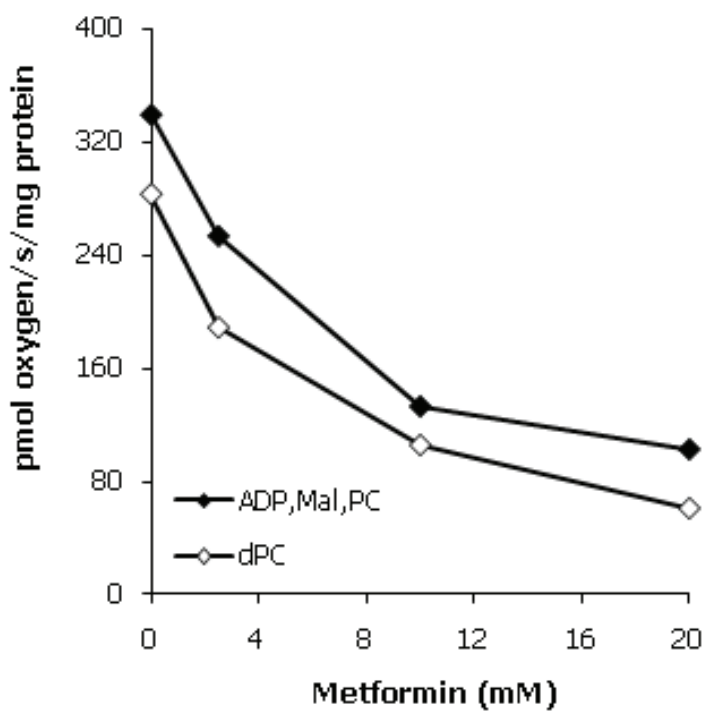

Fig. 3. The palmityl carnitine oxidation in rat liver homogenate $\mathbf{A}$ : the effect of single dose of metformin; B: concentration-dependent effect of metformin on palmityl carnitine oxidation. Palmityl carnitine oxidation was determined under condition described at Fig. 1, but BSA was not added. $12.5 \mu \mathrm{M}$ palmityl carnitine was added to the incubation medium with homogenate malate and ADP after 5 min equilibration with metformin. $\mathrm{dPC}$ were calculated as the difference of oxygen consumption in the presence of malate+ADP with and without palmityl carnitine. Data are representative values from two independent experiments.

Palmityl carnitine oxidation which involves both $\mathrm{NADH}$ - and flavoprotein-dependent dehydrogenases was inhibited at the same concentration range as oxidation of glutamate+malate (Fig. 3). Similarly, $60 \%$ inhibition of palmityl carnitine oxidation by $10 \mathrm{mM}$ metformin after 5 min preincubation, as with glutamate + malate was found 
(Fig. 3A). We evaluated both the maximum rate of palmityl carnitine oxidation in the presence of malate and ADP and the net increase of respiration induced by palmityl carnitine addition (Fig. 3A). Data in Fig. 3B show that both these parameters are inhibited by metformin similarly as glutamate+malate oxidation.

In agreement with previous findings, we found that succinate oxidation is not affected by metformin (see Fig. 1AB). Our data show that combination of two substrates, NADH-dependent glutamate and flavoproteindependent succinate, can fully saturate respiratory chain activity by electrons. Glutamate+malate (NADHdependent substrate) alone can not saturate respiratory chain capacity and succinate (flavoprotein-dependent substrate) was used to reach maximum values of the respiratory rate. However, when the complex I activity is decreased by metformin complex II activity can fully compensate this decrease of electron flow (see Fig. 1AB), both in liver homogenate and isolated mitochondria.

We may thus conclude that liver homogenate represents a very useful system for evaluation of metformin inhibitory effect on mitochondrial function. The results are comparable with those obtained on isolated mitochondria and the whole procedure is less labour- and time-consuming. Our measurements on homogenate also confirm previous findings indicating that intact cells are not required for the manifestation of metformin inhibitory effect. We further show that the respiratory control index, an important indicator of mitochondrial function, could also be well detected on samples of tissue homogenates.

\section{Conflict of Interest}

There is no conflict of interest.

\section{Acknowledgements}

This work was supported by the grants from IGA MH CR NS 10504-3 and the Institutional project AV0Z 501 10509 .

\section{References}

BAILEY CJ, TURNER RC: Metformin. New Engl J Med 334: 574-579, 1996.

BRADFORD MM: A rapid and sensitive method for the quantitation of microgram quantities of protein utilizing the principle of protein-dye binding. Anal Biochem 72: 248-254, 1976.

CAHOVÁ M, DRAHOTA Z, OLIVARNYK O, KUČERA O, DANKOVÁ H, KAZDOVÁ L: The effect of metformin on liver mitochondria and lipid metabolism in NAFLD. Diabetologia 53 (Suppl 1): S304, 2010.

CARVALHO C, CORREIA S, SANTOS MS, SELCA R, OLIVEIRA CR, MOREIRA PI: Metformin promotes isolated rat liver mitochondrial impairment. Mol Cell Bioch 308: 75-83, 2008.

ČERVINKOVÁ Z, RAUCHOVÁ H, KřIVÁKOVÁ P, DRAHOTA Z: Inhibition of palmityl carnitine oxidation in rat liver mitochondria by tert-butyl hydroperoxide. Physiol Res 57: 133-136, 2008.

EL-MIR M-Z, NOGUEIRA V, FONTAINE E, AVERET N, RIGOULET M: Dimethylbiguanide inhibits cell respiration via an indirect effect targeted on the respiratory chain Complex I. J Biol Chem 275: 223-228, 2000.

ENDLICHER R, KRIVAKOVA P, RAUCHOVA H, NUSKOVA H, CERVINKOVA Z, DRAHOTA Z: Peroxidative damage of mitochondrial respiration is substrate-dependent. Physiol Res 58: 685-692, 2009.

FORETZ M, HEBRARD S, LECLERC J, ZARRINPASHNEH E, SOTY M, MITHIEUX G, SAKAMOTO K, ANDREELLI F, VIOLLET B: Metformin inhibits hepatic gluconeogenesis in mice independently of the LKB1/AMPK pathway via a decrease in hepatic energy state. J Clin Invest 120: 2355-2369, 2010.

GNAIGER E, STEINLECHNER-MARAN R, MÉNDEZ G, EBERL T, MARGREITER R: Control of mitochondrial and cellular respiration by oxygen. J Bioenerg Biomembr 27: 583-596, 1995.

GUIGAS B, DETAILlE D, CHAUVIN C, BATANDIER C, DE OLIVEIRA F, FONTAINE E, LEVERVE X: Metformin inhibits mitochondrial permeability transition and cell death: a pharmacological in vitro study. Biochem J 382: 877-884, 2004.

HUNDAL RS, KRSSAK M, DUFOUR S, LAURENT D, LEBON V, CHANDRAMOULI V, INZUCCHI SE, SCHUMANN WC, PETERSEN KF, LANDAU BR, SHULMAN GI: Mechanism by which metformin reduces glucose production in type 2 diabetes. Diabetes 49: 2063-2069, 2000.

KŘIVÁKOVÁ P, LÁBAJOVÁ A, ČERVINKOVÁ Z, DRAHOTA Z: Inhibitory effect of t-butyl hydroperoxide on mitochondrial oxidative phosphorylation in isolated rat hepatocytes. Physiol Res 56: 137-140, 2007. 
OUSLIMANI N, PEYNET J, BONNEFONT-ROUSSELOT D, THEROND P, LEGRAND A, BEAUDEUX JL: Metformin decreases intracellular production of reactive oxygen species in aortic endothelial cells. Metabolism 54: 829-834, 2005.

OWEN MR, DORAN E, HALESTRAP AP: Evidence that metformin exerts its anti-diabetic effects through inhibition of complex lof the mitochondrial respiratory chain. Biochem J 348: 607-614, 2000.

SCHNEIDER WC, HOGEBOOM GH: Intracellular distribution of enzymes. 5. Further studies on the distribution of cytochrome-c in rat liver homogenates. J Biol Chem 183: 123-128, 1950.; 